\title{
Validation of the Utrecht Work Engagement Scale (UWES) in the Malaysian Context
}

\author{
Wan Shahrazad Wan Sulaiman and Nur Aisyah Zahoni
}

\begin{abstract}
Individuals' performance at work is determined to a certain extent on how engaged they are with the work they are doing. Hence a reliable and valid instrument must be used to accurately measure work engagement. This study aims to test the validity and reliability of the Utrecht Work Engagement Scale (UWES) in the Malaysian culture. The scale consists of three subscales which are vigor, dedication and absorption. This study involved 205 respondents who worked as salespersons in urban area in the capital city of Kuala Lumpur, Malaysia. They answered the UWES and three other questionnaires that assess job performance, turnover intention and job meaningfulness. The analysis showed that the validity using exploratory factor analysis managed to extract three factors. However, the factor structures of these three dimensions were slightly different than the original version. Reliability of the scale was satisfactory. The findings also showed significant relations with other criteria namely job performance, job meaningfulness and turnover intention. This study provided initial evidence that the instrument that can be used to measure work engagement in Malaysia. Some limitations and suggestions were recorded for the purpose of improvement for future research and guidance to organizations in developing effective work engagement.
\end{abstract}

Index Terms-Work engagement, reliability, validity, factor analysis.

\section{INTRODUCTION}

Through the emergence of positive psychology [1]-[3], together with the fact that there are limited positive constructs related with work well-being, the concept of work engagement has gained more attention in occupational health psychology [4].

High work engagement makes a person more motivated at work and increases their commitment. Work engagement makes an individual feel that their existence in the organization is meaningful for their lives to the extent that it touches the deepest level of their lives and this in turn will increase organizational performance. The relationship between work engagement and job performance is usually undesirable [5], organizational psychologists found that work attitude actually shows direct relationship with characteristics of good job performance. Two related concepts are usually used namely job involvement and work engagement. Job involvement is the degree in which an individual is involved cognitively and care about their jobs [6]. On the other hand, work engagement refers to the

Manuscript received March 10, 2015; revised May 9, 2015.

The authors are with the School of Psychology and Human Development, Faculty of Social Sciences and Humanities, Universiti Kebangsaan Malaysia, Malaysia (e-mail: shara@ukm.edu.my). individual's engagement and job satisfaction after having done the work with full of vigor [7]. These two terms have been defined widely by researchers in previous studies.

According to Bakker and Demerouti (2007), work engagement is a positive impact that is produced from being fully engaged during work [8]. Work engagement is acknowledged as positive, fulfilling and also work related with thoughts of vigor, dedication and absorption [9], [10], [11]. Work engagement comprises of three subscales namely vigor, dedication and absorption has been considered as an indicator of work well being which is stable and positive [12].

Work engagement is an important element for an organization as a basis that contributes towards the increase or decrease of performance [13], [14]. Recent studies show that work engagement is directly related with performance evaluation from supervisors [15], [16], financial status [17], and customer satisfaction [18]. Early research findings by Demerouti (2006) show that positive work experience flow does not necessarily produce positive work performance [19]. Although the difference of job performance between two different individuals has become a focus in the traditional model, the nature of flexibility in individual's performance is more meaningful [20], [21].

Confirmatory factor analysis (CFA) in theory has supported the UWES-17 structure based on the correlation between three factors namely, vigor, dedication and absorption [22]-[25]. All these studies have shown that the three work engagement factors have direct and high relationship with correlations ranging between 0.60 until 0.99 . Based on these high correlations, total factor analysis also was conducted to test the items in UWES as one factor [22], [23], [25]. However, the correlation of the three factor structure in theory has shown suitable significance and more dominant with alternative data that has received support from previous studies.

A psychometric study in China has tested the construct through the development of UWES. Apart from the three factor structure instrument in the original version with 17 items (UWES-17), there was also a shortened and revised nine-item version (UWES-9). This study tested the psychometric property based on the Chinese version by examining its validity, reliability, descriptive statistics and factor analysis. The survey was conducted in 2009 on 992 employees from more than 30 elderly home services in Hong Kong. Results of factor analysis produced three factors in UWES-9 which were more suitable to be used compared to UWES-17. This finding showed that the internal consistency was acceptable and a strong correlation based on the factors in the original version. Consequently, UWES-9 showed an 
acceptable psychometric property and its use supported the studies according to Chinese context [26].

Apart from that, a psychometric study of Japanese version UWES (UWES-J) was also conducted to examine whether UWES-J was suitable to be used. A total of $N=2334$ sample were used using independent sampling selection. Result of analysis of the whole construct did not change the three subscales namely vigor, dedication and absorption. The internal consistent of the scale was high with $\alpha=.92$ and test retest reliability within a two-month range was .66 [27].

In Malaysia, usually most of the psychological tests used originated from the West and based on the Western culture. Although most of these instruments were back translated, existing instruments cannot be ascertained whether it really measures the construct in the local context. In addition, established instruments are developed in English which is not the mother language of Malaysians. As a result, some of the items could not be understood completely even though it has been translated into Malay language. Therefore, this motivates the researcher to test the suitability of the instrument according to Malaysian culture even though the measurement was adapted from English version instruments.

\section{OBJECTIVES}

The objectives of this study is to: 1) test the construct validity of the UWES using factor analysis; 2) test the concurrent validity by correlating the scores of work engagement with job performance, job meaningfulness and turnover intention; and 3) test the reliability of the UWES using internal consistency method.

\section{METHOD}

This was a survey study using questionnaire to collect data and data analysis employed a quantitative method. Throughout the research, a number of 213 respondents above the age of 18 years old who worked as salespersons participated in this study. However, only 205 completed questionnaires were used to analyze the data. The respondents who participated in this study were selected using purposive sampling. They comprised of 55 male respondents $(26.8 \%)$ and 150 female respondents $(73.2 \%)$. Majority of the respondents $(87.8 \%)$ have worked as salespersons less than six months, while only $12.2 \%$ have worked as salespersons between six to 12 months.

A set of questionnaire consisting of four parts were used to collect the data and they were:

1) The Utrecht Work Engagement Scale (UWES) [22] consisting 17 items and measuring three subscales which are six items measuring vigor, five items measuring dedication and six items measuring absorption. Respondents answered the scale using a seven-point likert scale with 0 indicating Never and 7 indicating Always. Schaufeli and Bakker (2003) reported that the UWES has reliability ranging from .80 to $.90[28]$.

2) The Contextual and Task Performance Scale which was developed by Goodman and Svyantek (1999) [29]. The contextual performance has seven items while the task performance contains nine items. The items were scored based on a four-point Likert scale with 1=Strongly Disagree, 2=Disagree, 3=Agree and 4=Strongly Agree. A high reliability was obtained for this scale with $\alpha=.74$ [30].

3) The Turnover Intention Scale was measured by 6-items. Three items were taken from a study by Shore and Martin (1989) while another three items were from Simmon, Cochran and Blount's (1997) study [31]-[32]. The scale uses a five-point likert scale with $1=$ Strongly Disagree, 2=Disagree, 3=Uncertain, 4=Agree and 5=Strongly Agree. The scale has a high degree of reliability with $\alpha=.92$ and $\alpha=.89$ [30].

4) The Job Meaningfulness Scale consists of six items from a study by May et al. (2004) [33]. Reliability of this scale was $\alpha=.70$ [33].

TABLE I: FACTOR STRUCTURE OF THE 17-ITEM UWES

\begin{tabular}{cccc}
\hline Subscale & $\mathbf{1}$ & $\mathbf{2}$ & $\mathbf{3}$ \\
\hline Subscale 1, Eigen value $=2.411, \%$ Variance & & &
\end{tabular}

$=14.19$

Item8 When I get up in the morning, I feel like

going to work

Item9 I feel happy when I am working

intensely.

Item10 I am proud of the work that I do.

Item11 I am immersed in my work.

Item12 I can continue working for very long .311 periods at a time.

Item13 To me, my job is challenging.

Item14 I get carried away when I'm working.

Subscale 2, Eigen value $=1.586, \%$ Variance $=9.33$

Item1 At my work, I feel bursting with energy.

Item 4 At my job, I feel strong and vigorous.

Item5 I am enthusiastic about my job.

Item6 When I am working, I forget everything else around me.

Item7 My job inspires me.

Item16 It is difficult to detach myself from my

.011 job.

\footnotetext{
Subscale 3, Eigen value $=1.293, \%$ Variance $=7.61$

Item2 I find the work that I do full of meaning and purpose.
}

Item3 Time flies when I'm working.

Item15 At my job, I am very resilient, .395 mentally.

Item17 At my work I always persevere, even .488 when things do not go well. 


\section{RESUlTS AND DisCUSSION}

Construct validity of the UWES was conducted using factor analysis with the aim to testing whether factor analysis can generate subscales or components or factors as suggested by Schaufeli et al. (2002) [25]. Factor analysis conducted in the present study used principal component analysis and varimax rotation with scree plot to test the data obtained in this study. Before that, samples were tested to determine whether it fulfills the measurement sampling adequacy by using Measures of Sampling Adequacy Kaiser-Meyer-Olkin (KMO). The results obtained showed KMO value was .608. According to Brace et al. (2006), KMO values that can be accepted is .60 and its value is better when it reaches 1.0 [34]. For this study, the KMO value obtained was .608 indicating an acceptable value. The KMO value showed that the sample was adequate and significant $(p<0.01)$. According to Hair $e t$ al. (2005), factor analysis can be conducted if the Sphericity Bartlett Test is significant at $p<0.05$ [35].

The results of factor analysis by using principal component analysis and varimax rotation and scree plot extracted three factors which contributed a total of $31.12 \%$ variance and produced loadings between .321 and .795 . The results are presented in Table I.

The results obtained showed that three items have very poor loadings. These items were items 4, 14 and 16 with loadings between .011 until .068. After examining these items, the researchers found that the meaning of these items were unsuitable and have to be eliminated.

Factor analysis was conducted again on 14 items. The results of factor analysis by using principal component analysis and varimax rotation and scree plot still managed to extract three factors which contributed a total of $36.64 \%$ variance and produced loadings between .321 and .795. These three factors extracted represent somewhat different subscales than the original version of the UWES. The results are presented in Table II.

Based on the analysis of the items retained after factor analysis was conducted, three subscales were compared again with the subscales in the original version. The first factor which was vigor was renamed as Excitement consistent with the changes in the items loaded in this subscale. This subscale consisted of five items and they were items 8, 9, 10, 11 and 13. An example of the item in Excitement is "When I get up in the morning, I feel like going to work".

The second and third factors were retained as Dedication and Absorption. However, results showed that the items categorized under these two subscales have changed. The Dedication subscale consisted of four items and they were items 1, 5, 6 and 7. An example of item for this subscale was "My job inspires me". Finally, the third subscale was Absorption which consisted of five items and they were items $2,3,12,15$ and 17 . This subscale retained the theme of absorption as the meaning of these five items indicated individuals being absorbed in work such as "Time flies when I'm working".

The second objective aims to evaluate the concurrent validity of the UWES. Pearson correlation analysis was used to examine the relationship between the UWES with other criteria specifically job performance, job meaningfulness and turnover intention which were theoretically related based on previous studies. The results between work engagement measured by the UWES and scores of job performance showed a significant and positive relationship, $r=.541$, $p<0.01$. Concurrent validity of the UWES based on the correlation between work engagement and job meaningfulness showed a significant and positive relationship, $r=.828, \quad p<0.01$. Finally, the relationship between work engagement and turnover intention was significant and negative, $r=-.657, p<0.01$ which also provided evidence of concurrent validity for the instrument.

The third objective aims to examine the reliability of the UWES using internal consistency method. Results showed that alpha Cronbach for the whole instrument was .514. Results of alpha Cronbach according to subscale showed that mixed results with Factor $1=.663$, Factor $2=.358$ and Factor $3=.227$.

TABLE II: FACTOR STRUCTURE OF THE 14-ITEM UWES

\begin{tabular}{lccc}
\hline Subscale & $\mathbf{1}$ & $\mathbf{2}$ & $\mathbf{3}$ \\
\hline Subscale 1, Eigen value $=2.396, \%$ Variance & & &
\end{tabular}

$=17.12$

Item8 When I get up in the morning, I feel like $\quad .348$ going to work

Item9 I feel happy when I am working

intensely.

Item10 I am proud of the work that I do. $\quad .576$

Item11 I am immersed in my work. $\quad .795$

Item13 To me, my job is challenging.

Subscale 2, Eigen value $=1.442, \%$ Variance

$=10.30$

Item1 At my work, I feel bursting with energy.

Item5 I am enthusiastic about my job.

Item6 When I am working, I forget everything else around me.

Item7 My job inspires me.

Subscale 3, Eigen value $=1.290, \%$ Variance $=9.22$

Item2 I find the work that I do full of meaning and purpose.

Item3 Time flies when I'm working.

Item12 I can continue working for very long periods at a time.

Item15 At my job, I am very resilient, mentally.

Item17 At my work I always persevere, even when things do not go well.

Results of the present study found that construct validity of the UWES was below satisfactory as a different three-factor structure was obtained. Although results of factor analysis were able to extract a three-factor structure as was suggested by the developers, there were items that loaded on different 
factors. Piia Seppala et al. (2009) opined that the UWES have some problems in its construct validity when it was used on different individuals, groups and organizations [36].

Items such as item 4,14 and 16 were eliminated due to its unsuitability according to Malaysian culture. This can be explained through item 14 that states "I get carried away when I'm working" in which when it was translated into Malay language means that a person is so absorbed in his or her work. This translation from English which in the original language has a positive meaning gives a negative meaning in the Malaysian context. This shows that a person who is too focused in his or her work to the extent that he or she ignores what is happening around him or her.

Based on the psychometric properties of the UWES, the results found that it differed with the original version. This can happen due to the difference in the cultural context of the West and Malaysia. One element in the Malaysian culture is the practice of cooperation and teamwork. The spirit of togetherness and sportsmanship is one aspect that is closely related with the lifestyle and culture of Malaysia. In the context of Malay community for instance, teamwork culture has become an identity and inherited in the community. Work engagement on the other hand, is more individual in nature. This can be seen through the meaning of absorption or absorbed in work.

\section{CONCLUSION}

This study aims to test the reliability and validity of the Utrecht Work Engagement Scale (UWES) in the Malaysian culture. Generally, this study was able to show the psychometric properties of the UWES. Although, results showed a three-factor solution but its items were loaded on different factors than the original version. This needs more future research to identify cultural specificity of work engagement and how Malaysians perceive as desirable work engagement in order for this construct to depict positive aspect of work behavior.

\section{REFERENCES}

[1] M. E. P. Seligman, "Positive psychology: Fundamental assumptions," Psychologist, pp. 126-127, 2003.

[2] M. Seligman and M. Csikszentmihalyi, "Positive psychology: An introduction," American Psychologist, vol. 55, pp. 5-14, 2000.

[3] N. Turner, J. Barling, and A. Zacharatos, "Positive psychology at work," in Handbook of Positive Psychology, C. R. Snyder and S. J. Lopez, Eds. New York: Oxford University Press, 2002, pp. 715-728.

[4] W. B. Schaufeli and M. Salanova, "Work engagement: An emerging psychological concept and its implications for organizations," Research in Social Issues in Management, CT: Information Age Publishers, 2007, pp. 135-177.

[5] T. A. Judge, A. Erez, J. E. Bono, and C. J. Thoresen, "The core self-evaluations scale: Development of a measure," Personnel Psychology, vol. 56, pp. 303-331, 2003.

[6] I. M. Paullay, G. M. Alliger, and E. F. Stone-Romero, "Construct validation of two instruments designed to measure job involvement and work centrality," Journal of Applied Psychology, vol. 79, pp. 224-228, 1994.

[7] J. K. Harter, F. L. Schmidt, and T. L. Hayes, "Business-level-unit relationship between employee satisfaction, employee engagement, and business outcomes: A meta-analysis," Journal of Applied Psychology, vol. 87, no. 2, pp. 268-279, 2002.

[8] A. B. Bakker and E. Demerouti, "The job demands-resources model: State of the art," Journal of Managerial Psychology, vol. 22, pp. 309-328, 2007.
[9] V. Gonza'lez-Roma', W. B. Schaufeli, A. B. Bakker, and S. Lloret, "Burnout and work engagement: Independent factors or opposite poles?" Journal of Vocational Behavior, vol. 68, pp.165-174, 2006.

[10] C. Maslach, W. B. Schaufeli and M. P. Leiter, "Job burnout," Annual Review of Psychology, vol. 52, pp. 397-422, 2001.

[11] W. B. Schaufeli, A. B. Bakker, and M. Salanova, "The measurement of work engagement with a short questionnaire," Educational and Psychological Measurement, vol. 66, pp. 701-716, 2006.

[12] W. B. Schaufeli and A. B. Bakker, "Job demands, job resources, and their relationship with burnout and engagement: A multi-sample study," Journal of Organizational Behavior, vol. 25, pp. 293-315, 2004.

[13] E. Demerouti and R. Cropanzano, "From thought to action: Employee work engagement and job performance," in A. B. Bakker and M. P. Leiter (Eds.), Work Engagement: A Handbook of Essential Theory and Research, Hove, UK: Psychology Press, 2010, pp. 147-163.

[14] W. H. Macey and B. Schneider, "The meaning of employee engagement," Industrial and Organizational Psychology, vol. 1, no. 1, pp. 3-30, 2008.

[15] A. B. Bakker and P. M. Bal, "Weekly work engagement and performance: A study among starting teachers," Journal of Occupational and Organizational Psychology, vol. 83, pp. 189-206, 2010.

[16] J. R. B. Halbesleben and A. R. Wheeler, "The relative roles of engagement and embeddedness in predicting job performance and intention to leave," Work and Stress, vol. 22, pp. 242-256, 2008.

[17] D. Xanthopoulou, A. B. Bakker, E. Demerouti, and W. B. Schaufeli, "Work engagement and financial returns: A diary study on the role of job and personal resources," Journal of Occupational and Organizational Psychology, vol. 82, pp. 183-200, 2009.

[18] M. Salanova, S. Agut and J. M. Peiro, "Linking organizational resources and work engagement to employee performance and customer loyalty: The mediation of service climate," Journal of Applied Psychology, vol. 90, no. 6, pp. 1217-1227, 2005.

[19] E. Demerouti, "Job characteristics, flow, and performance: The moderating role of conscientiousness," Journal of Occupational Health Psychology, vol. 11, pp. 266-280, 2006.

[20] D. L. Deadrick, N. Bennett, and C. J. Russell, "Using hierarchical linear modeling to examine dynamic performance criteria over time," Journal of Management, vol. 23, pp. 745-757, 1997.

[21] C. D. Fisher and C. S. Noble, "A within-person examination of correlates of performance and emotions while working," Human Performance, vol. 17, pp. 145-168, 2004.

[22] W. B. Schaufeli and A. B. Bakker, "Utrecht work engagement scale: Preliminary manual," Occupational Health Psychology Unit, pp. 1-58, 2003.

[23] U. E. Hallberg and W. B. Schaufeli, "Same same" but different? Can work engagement be discriminated from job involvement and organisational commitment?" The European Psychologist, vol. 11, pp. 119-127, 2006.

[24] Hakanen, "Fromburnout to job engagement - validation of the Finnish version of an instrument formeasuring job engagement (UWES) in an educational organization," Tyo" ja Ihminen, vol. 16, pp. 42-58, 2002.

[25] W. B. Schaufeli, M. Salanova, V. Gonzales-Roma, and A. B. Bakker, "The measurement of engagement and burnout: A two sample confirmatory factor analytic approach," Journal of Happiness Studies, vol. 3, pp. 71-92, 2002.

[26] T. C. Fong and S. Ng, "Measuring engagament at work: Validation of the Chinese version of the Utrecht work engagament scale," International Journal of Behavioral Medicine, vol. 10, 2011.

[27] A. Shimazu et al., "Work engagement in Japan: Validation of the Japanese version of the Utrecht work engagament scale," Applied Psychology, vol. 57, no. 3, pp. 510-523, 2008.

[28] W. B. Schaufeli and A. B. Bakker, "Test manual for the Utrecht work engagement scale," Unpublished manuscript, Utrecht University, the Netherlands.

[29] S. A. Goodman and D. J. Svyantek, "Person-organization fit and contextual performance: Do shared values matter?" Journal of Vocational Behavior, vol. 55, pp. 254-274, 1999.

[30] S. Saeed, S. Yousafzai, and A. Engelen, "On cultural and macroeconomic contingencies of the entrepreneurial orientation-performance relationship," Entrepreneurship Theory and Practice, vol. 38, no. 2, pp. 255-290, 2014.

[31] L. M. Shore and H. J. Martin, "Job satisfaction and organizational commitment in relation to work performance and turnover intentions," Human Relations, vol. 42, no. 7, pp. 625-638, 1989.

[32] C. Simmons, J. Cochran, and W. Blount, "The effects of job-related stress and job satisfaction on probation officers' inclinations to quit," 
American Journal of Criminal Justice, vol. 21, no. 2, pp. 213-229, 1997.

[33] D. R. May, R. L. Gilson, and L. M. Harter, "The psychological conditions of meaningfulness, safety and availability and the engagement of the human spirit at work," Journal of Occupational and Organisational Psychology, vol. 77, pp. 11-37, 2004.

[34] N. Brace, R. Kemp and R. Snelgar, "SPSS for psychologists," Houndmills, Basingstoke, Hampshire: Palgrave Macmillan, 2006.

[35] J. F. Hair, W. Black, B. Babin, R. E. Anderson and R. L. Tatham, Multivariate Data Analysis, Upper Saddle River, NJ: Prentice Hall, 2005.

[36] P. Seppälä, S. Mauno, T. Feldt, J. Hakanen, U. Kinnunen, A. Tolvanen et al., "The construct validity of the Utrecht work engagement Scale: Multisample and longitudinal evidence," Journal of Happiness Studies, vol. 10, 459-481, 2009

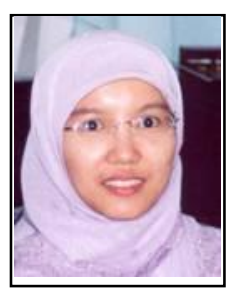

Wan Shahrazad Wan Sulaiman is a lecturer and an associate professor at Universiti Kebangsaan Malaysia (UKM). She received her bachelor of human sciences (psychology) (Hons) from International Islamic University Malaysia (IIUM). She received her master's of arts (psychology) from Universiti Kebangsaan Malaysia. She also received her doctor of philosophy (psychology) from International Islamic University
Malaysia (IIUM).

She started her academic career as a tutor in 1995 at University Kebangsaan Malaysia, then was appointed as a lecturer in 2002. In 2009 she was appointed as a senior lecturer and was promoted to an associate professor in 2012. Her field of specialization is psychometrics. Among her research interests are application of psychological tests, adaptation and standardization of psychological tests among prisoners for parole evaluation, psychological profile of drug addicts, personality profile of adolescents and juvenile delinquents, and assessment of critical thinking ability among university students.

Wan Shahrazad is a board member and lifetime member of Malaysian Psychological Association (PSIMA). She is also a member of International Association of Applied Psychology. Her publications have been published in several journals such as World Applied Sciences Journal, American Journal of Applied Sciences, The Social Science, Asian Social Science, Ethics and Behavior, and Pertanika Journal of Social Sciences and Humanities. 